\title{
Análise Estocástica de Fluxo e Transporte em Solos Não Saturados para Avaliação de Risco de Salinização
}

\author{
Suzana Maria G. L. Montenegro \\ Grupo de Recursos Hídricos - Depto. de Eng. Civil - UFPE - Av. Acad. Hélio Ramos, s/n - Cidade Universitária \\ 50740-530 Recife, PE - smglm@npd.ufpe.br \\ Rae Mackay \\ School of Earth Sciences - Birmingham University - UK - r.mackay@bham.ac.uk
}

\author{
Abelardo A. de A. Montenegro \\ Departamento de Tecnologia Rural - UFRPE - Av. Dom Manoel de Medeiros - Dois Irmãos \\ 50000-000 Recife, PE - monte@hotlink.com.br
}

Recebido: 15/10/01 - revisão: 13/12/01 - aceito: 14/03/02

\begin{abstract}
RESUMO
A necessidade de irrigação para a prática da agricultura no nordeste do Brasil e a irregularidade e pouca disponibilidade de águas superficiais em algumas áreas, além da baixa incidência de estruturas hídricas para o seu aproveitamento, colocam as águas subterrâneas como única alternativa para suprimento de água. No entanto, grande parte da região nordeste é composta por formações do tipo cristalino, com limitada capacidade de armazenamento e dificuldades de extração de grandes vazões dos mesmos. Por essa razão, a agricultura familiar, ou agricultura em pequena escala, vem se desenvolvendo no vales de rios, na maioria intermitentes, aproveitando águas subterrâneas dos aqüiferos aluvionares. A vulnerabilidade desses sistemas à salinização, com prejuizos ao solo, água subterrânea e produtividade das culturas, exige a aplicação de ferramentas de diagnóstico, para que medidas de controle, ou do manejo da irrigação possam ser propostas. Esse trabalho apresenta metodologia de análise estocástica espacial de fluxo de água e transporte de soluto na zona não saturada aplicada a análise de risco de salinização. Como estudo de caso, enfoca-se um lote de uma área irrigada sobre aluvião no Agreste do Estado de Pernambuco. Exemplos de aplicação e potencialidades de uso da metodologia são apresentados. Destaca-se a necessidade de obtenção de mais dados de campo para a efetiva aplicação da metodologia. A análise estocástica apresentada pode ser aplicada a análise de outros problemas de risco de contaminação da água no solo.
\end{abstract}

Palavras-chave: salinização; zona não saturada; aqüífero aluvial; variabilidade espacial; análise estocástica.

\section{INTRODUÇÃO}

O decréscimo de disponibilidade dos recursos hídricos superficiais, aliado a elevados custos de armazenamento, captação, adução e tratamento, vêm colocando as águas subterrâneas em posição de destaque no Brasil nas últimas décadas. Algumas regiões do país são detentoras de enorme potencial de águas subterrâneas, com capacidade para abastecimento de até grandes centros urbanos. Essas regiões se caracterizam por possuírem bacias do tipo sedimentar, com grande potencial de armazenamento de águas subterrâneas. Mesmo em regiões onde o armazenamento de águas subterrâneas é restrito pela presença de formações rochosas a pou- ca profundidade, caracterizando as bacias do tipo cristalino, os aqüíferos aluvionares nas adjacências de cursos d'água constituem importante reserva subterrânea, notadamente para abastecimento de projetos de irrigação de pequeno porte, a exemplo do que ocorre no Nordeste brasileiro (Silva, 2000) e em outras regiões áridas e semi-áridas (Carter \& Alkali, 1996).

Uma das mais severas ameaças à qualidade das águas subterrâneas é a concentração excessiva de sais. A salinidade da água no subsolo em níveis elevados impõe restrições ao seu uso não só para o consumo humano e animal como também no desenvolvimento da agricultura. A salinidade reduz a disponibilidade de água para a cultura, afetando 
seu desenvolvimento e produtividade. As causas de salinização das águas subterrâneas estão relacionadas a processos naturais, pela dissolução de minerais presentes no solo e pelo transporte através da atmosfera de sais de origem marinha, e a processos induzidos pela ação do homem. Nesse último caso, pode ser destacada em regiões semi-áridas a salinização provocada por evaporação em áreas com lençol freático elevado, em decorrência da prática da irrigação, denominada salinização secundária (Ghassemi et al., 1991). A salinização secundária afeta grandes extensões de áreas em regiões áridas e semi-áridas na Argentina, China, Egito, Índia, Irã, Iraque, Paquistão, Tailândia e Estados Unidos (Ghassemi et al., 1991).

No Brasil, não há levantamento recente das áreas afetadas por salinização secundária, mas Goes (1978) estimou que nos projetos de irrigação implantados pelo DNOCS (Departamento Nacional de Obras contra às Secas) de 25 a 30\% da área foi afetada por salinização. A salinização dos solos é um dos processos que podem conduzir à desertificação, definida como a degradação dos recursos naturais, incluindo solo e água, e a redução da qualidade de vida das populações afetadas. Além disso, com a ocorrência de precipitações, os sais presentes na zona não saturada do solo podem ser transportados para o aqüífero, incrementando o seu nível de salinidade. Em conseqüência, esses sais podem voltar à zona não saturada pelo processo de ascensão capilar. O ciclo criado pode degradar tanto solo quanto aqüífero.

A identificação da dinâmica da salinização da água no subsolo é fator indispensável para o estabelecimento de práticas de controle do processo e proposições de uso da água com teores elevados de salinidade, utilizando culturas tolerantes. Modelos matemáticos de fluxo de água e transporte de solutos na zona não saturada constituem importante ferramenta de análise da dinâmica de salinização de áreas irrigadas sobre aqüíferos aluviais. Os modelos devem considerar a dinâmica na zona não saturada, ou no sistema solo-planta atmosfera e a interação com o lençol subterrâneo. Como os solos são formações naturalmente heterogêneas e essa heterogeneidade influencia de forma marcante os processos de fluxo e transporte (Cambardella et al., 1994), esse aspecto deve ser levado em consideração na análise do processo de salinização (Russo, 1984). A variabilidade espacial das propriedades hidráulicas dos solos e os erros de determinação dessas propriedades constituem incertezas ao pro- cesso de modelagem. Uma abordagem determinística do problema não permite a consideração dessas incertezas. Assim, uma abordagem estocástica espacial é necessária para a análise do problema, permitindo uma avaliação de risco do processo de salinização. Nesse contexto, o termo "risco" é empregado no sentido de probabilidade de excedência de valores limites de concentração de sais na solução da água no solo, segundo critérios pré-estabelecidos na literatura, considerando-se as incertezas inerentes às propriedades hidráulicas do solo, decorrentes de erros de determinação e variabilidade espacial.

O presente artigo apresenta proposição de metodologia de análise de risco de salinização em áreas irrigadas sobre aquuíferos freáticos rasos, focalizando como estudo de caso uma planície aluvionar no Agreste do Estado de Pernambuco. É importante destacar que a metodologia apresentada e discutida nesse artigo enfocando o problema de salinização pode ser aplicada, com as devidas considerações particulares, a problemas de contaminação da zona não saturada e o efeito na qualidade da água de recarga do lençol por aporte de agrotóxicos, contaminantes orgânicos, vinhaça (fertirrigação), entre outros, a exemplo da aplicação no transporte de nitrato apresentada por Wu et al. (1997).

\section{MODELO CONCEITUAL DE FLUXO DE ÁGUA E TRANSPORTE DE SOLUTO NA ZONA NÃO SATURADA DE SISTEMAS HETEROGÊNEOS}

Estudos revelaram que a análise estocástica de fluxo de água e transporte de solutos na zona não saturada de pequena profundidade (poucos metros abaixo da superfície do solo) pode ser realizada assumindo que o domínio é representado por uma série de colunas de solo homogêneas, com propriedades médias ao longo de sua profundidade, e hidraulicamente independentes, ou seja, sem interação lateral e com fluxo e transporte ocorrendo na direção vertical. Entre as colunas, ou seja, no plano horizontal, as propriedades hidráulicas dos solos variam estocasticamente de acordo com o modelo de estrutura de correlação espacial inferido, que representa a heterogeneidade e os erros de determinação. A consideração da correlação espacial entre as colunas de solo, representando diferentes locações de campo, permite a análise da distribuição espacial das variáveis de fluxo e transporte, diferentemente da abordagem determinística. Esse modelo conceitual é conhecido como modelo de 
colunas paralelas e foi inicialmente proposto por Dagan \& Bresler (1979), tendo sido largamente utilizado, e posteriormente analisado por diversos pesquisadores (por exemplo, Protopapas \& Bras, 1991; Ellsworth et al., 1991; Russo, 1991), que o consideram adequado para situações em que a aplicação de água na superfície do solo é feita através de fontes não pontuais e de maneira uniforme. De acordo com Jury et al. (1987), a consideração de colunas de solo homogêneas com propriedades médias ao longo da profundidade pode ser aceita como uma boa aproximação para problemas envolvendo áreas agrícolas, uma vez que as dimensões no plano horizontal são muito maiores dos que a extensão vertical em análise, ou seja, poucos metros abaixo da superfície do solo. As análises que são apresentadas da literatura quanto a consistência, limitações e validade das hipóteses assumidas no modelo de colunas paralelas não se limitam a questões regionais e sim a condições genéricas de uso da formulação.

Modelos simplificados foram utilizados no passado (por exemplo, Bresler \& Dagan, 1983; Russo, 1984) na análise estocástica, mas a não consideração de processos físicos importantes restringe sua aplicabilidade. Modelos robustos, do tipo multi-componentes, foram aplicados a estudos de manejo de salinidade em abordagem determinística considerando o domínio de estudo representado por uma única coluna de solo, com propriedades médias da área (Nour el - Din, 1987; Cardon \& Letey, 1992). Para a realização da análise estocástica propõe-se a utilização de um modelo determinístico de fluxo e transporte descrevendo os processos físicos que ocorrem na zona não saturada, que deve ser aplicado a repetidas simulações de forma a cobrir a distribuição de probabilidades do parâmetro hidráulico, através do procedimento de Monte Carlo. Essa formulação, apesar da demanda computacional relativamente elevada, pode oferecer o entendimento da complexidade dos fenômenos envolvidos na acumulação de sais em áreas irrigadas, incluindo o efeito resultante em plantas e no lençol freático.

Muitos estudos foram realizados visando caracterizar a variabilidade espacial de propriedades relacionadas ao fluxo de água e ao transporte de solutos em solos não saturados (por exemplo, Niesen et al., 1973; Russo \& Bresler, 1981; Istok et al., 1994). White (1988) e Jury et al. (1992) apresentaram tabelas mostrando intervalos aproximados de coeficientes de variação de determinadas propriedades hidráulicas do solo medidas em campo. Os referidos pesquisadores destacam que as propriedades relacionadas ao conteúdo de umidade e ao potencial matricial da água no solo exibem uma variabilidade espacial muito menor do que a condutividade hidráulica. Dagan \& Bresler (1983) realizaram análise estocástica de fluxo e transporte para estimativa de concentrações de sais em solos não saturados aplicando a abordagem do modelo de colunas paralelas, considerando que apenas a condutividade hidráulica saturada exibe variabilidade espacial. Essa consideração foi baseada nos resultados de análise efetuada por Russo \& Bresler (1982) que indicaram um impacto limitado na estimativa de concentrações de sais em problema semelhante da consideração da variabilidade espacial conjuntamente da condutividade hidráulica saturada e de outros parâmetros de água no solo quando comparada com a consideração da variabilidade espacial apenas da condutividade hidráulica saturada.

Se apenas um parâmetro é escolhido como variável estocástica na abordagem em questão, tem-se então a análise estocástica com distribuição paramétrica univariada. No caso em que a variabilidade espacial de diversos parâmetros é levada em consideração, tem-se a análise estocástica com distribuição de parâmetros multivariada, onde também é considerada a correlação entre os parâmetros. Os experimentos de Monte Carlo em análises multivariadas são claramente bem mais laboriosos do que os de análise univariada. Alternativamente, a análise estocástica multivariada pode ser efetuada através de metodologia baseada na consideração de um fator de escala, com significado físico, através do qual se representa a variabilidade espacial de diversos parâmetros de água no solo simultaneamente (Jury et al., 1997; Antonino et al., 1998). No entanto, a metodologia também apresenta diversos pontos em controvérsia quanto a sua aplicação, principalmente no que diz respeito à derivação desse fator de escala a partir de dados de campo dos parâmetros de água no solo. A análise estocástica efetuada nesse trabalho será baseada no Método de Monte Carlo, cuja aplicação a problemas semelhantes, vem se mostrando eficiente na caracterização da função de probabilidade da variável de interesse.

\section{MODELO DETERMINÍSTICO}

O modelo determinístico escolhido para a análise estocástica foi o WAVE (Vanclooster et al., 1994), que se baseia na equação de Richards, Equação (1), e na equação de convecção-dispersão, Equação (2), para a solução de problema de fluxo de água e transporte de soluto na direção vertical de uma coluna de solo. A equação de Richards na forma como é utilizada no modelo é escrita como: 


$$
\frac{\partial \mathrm{h}}{\partial \mathrm{t}}=\frac{1}{\mathrm{C}(\mathrm{h})} \frac{\partial}{\partial \mathrm{z}}\left[\mathrm{K}(\mathrm{h})\left(\frac{\partial \mathrm{h}}{\partial \mathrm{z}}+1\right)\right]-\frac{\mathrm{S}(\mathrm{h})}{\mathrm{C}(\mathrm{h})}
$$

onde $\mathrm{h}$ é o potencial matricial [L]; $\mathrm{t}$ o tempo [T]; $\mathrm{K}(\mathrm{h})$ a função de condutividade hidráulica do solo [L/T]; z a coordenada vertical [L]; $\mathrm{S}(\mathrm{h})$ a função de extração da água do solo pela planta, em relação ao potencial matricial $\left[\mathrm{T}^{-1}\right]$ e; $\mathrm{C}(\mathrm{h})=\mathrm{d} \theta / \mathrm{dh}$ a capacidade específica de água $\left[\mathrm{L}^{-1}\right]$.

A equação de convecção-dispersão considerada no modelo é:

$$
\frac{\partial(\theta \mathrm{C})}{\partial \mathrm{t}}+\frac{\partial(\mathrm{v} \theta \mathrm{C})}{\partial \mathrm{z}}=\frac{\partial}{\partial \mathrm{z}}\left(\theta \mathrm{D} \frac{\partial \mathrm{C}}{\partial \mathrm{z}}\right)
$$

onde $\theta$ é o conteúdo de umidade do solo $\left[\mathrm{L}^{3} / \mathrm{L}^{3}\right] ; \mathrm{C}$ a concentração de soluto $\left[\mathrm{M} / \mathrm{L}^{3}\right] ; \mathrm{v}$ a velocidade da água no meio poroso $[\mathrm{L} / \mathrm{T}] \mathrm{e}$; $\mathrm{D}$ o coeficiente de dispersão longitudinal $\left[\mathrm{L}^{2} \cdot \mathrm{T}^{-1}\right]$.

Assume-se que o coeficiente $\mathrm{D}$ é escrito como $\mathrm{D}=\lambda_{\mathrm{l}} \mathrm{V}$, onde $\lambda_{1}$ é o coeficiente de dispersividade hidrodinâmica. Para o estudo proposto, a concentração de soluto, $\mathrm{C}$, é tomada como o total de sólidos dissolvidos, representando a concentração de sais em solução na água, e o soluto é considerado inerte. A função $S(h)$ é definida no WAVE de acordo com modelo proposto por Feddes et al. (1978) escrito como:

$$
S(h)=\alpha(h) \cdot S_{\max }
$$

onde $S_{\max }$ é máxima retirada de água pela planta, que ocorre em condições ótimas de umidade, e $\alpha(h)$ é uma função adimensional de redução em resposta a uma condição não favorável de umidade, relacionada ao potencial matricial, h. No modelo WAVE a função $S_{\max }$ é dada por:

$$
\mathrm{S}_{\max }=\mathrm{a}-\mathrm{bz}
$$

onde $\mathrm{a}$ e $\mathrm{b}$ são constantes que devem ser preferencialmente determinadas através de experimentos.

A função $\alpha(h)$ é considerada no modelo WAVE de acordo com a proposição de Feddes et al. (1978) como dependente de quatro parâmetros, $h_{0}$, $\mathrm{h}_{1}, \mathrm{~h}_{2}$ e $\mathrm{h}_{3}$. $\mathrm{O}$ valor de $\mathrm{h}_{0}$ reflete as condições de deficiência de oxigênio para a planta, quando o nível de umidade do solo é alto, enquanto $h_{3}$ caracteriza a condição de estresse hídrico, ou de escassez de umidade, que prejudica o desenvolvimento da planta de forma irreversível, representado pelo ponto de murcha permanente. Os valores de $h_{0}$ e $h_{3}$ caracterizam valores-limite de tensão de água no solo, ou de pressão matricial, para que a extração de água pela planta cesse. Para valores de $\mathrm{h}$ superiores a ho e inferiores a $h_{3}$, a função de redução $\alpha(h)$ assume o valor zero. Entre $h_{1}$ e $h_{2}$ a planta teria condições ótimas de umidade e o valor de $\alpha$ é igual à unidade. No intervalo entre $h_{0} \mathrm{e} h_{1}$, uma variação linear de $\alpha$ é assumida. Uma opção de variação linear ou hiperbólica é assumida para $\alpha$ entre $h_{2}$ e $h_{3}$. Nesse estudo, uma variação linear foi assumida nesse intervalo.

O modelo considera que a extração de água pelas raízes integrada ao longo do comprimento da zona radicular, $\mathrm{z}_{\mathrm{r}}$, é limitada ao valor da transpiração potencial:

$$
\left(\int_{0}^{z_{r}} \mathrm{~S}(\mathrm{~h}, \mathrm{z}) \leq \mathrm{T}_{\mathrm{p}}\right)
$$

A transpiração potencial $T_{p}$ é calculada por um modelo de repartição da evapotranspiração potencial escrito como:

$$
\mathrm{E}_{\mathrm{p}}=\exp (-0,6 \cdot \mathrm{IAF}) \cdot \mathrm{ET}_{\mathrm{p}}
$$

onde $\mathrm{E}_{\mathrm{p}}$ é a evaporação potencial; IAF o índice de cobertura foliar $\mathrm{e} ; \mathrm{ET}_{\mathrm{p}}$ a evapotranspiração potencial.

$\mathrm{O}$ índice de cobertura foliar é definido como a razão entre a área efetiva da cobertura das folhas e a área da sua projeção no solo. A evapotranspiração potencial no modelo WAVE pode ser calculada através de valores fornecidos de evaporação do tanque classe A e coeficiente de cultura.

O modelo WAVE discretiza as Equações (1) e (2) através do Método das Diferenças Finitas. Para a solução da Equação (1) é necessário o conhecimento da curva característica do solo, $\theta(\mathrm{h})$, e da condutividade hidráulica como função do potencial matricial ou da umidade $(K(h))$ ou $K(\theta))$. É comum descrever essas relações através de fórmulas matemáticas, algumas já bastante consagradas como as funções de Brooks \& Corey (1964) e as de Van Genuchten (1980). A escolha das funções que melhor representam o comportamento do solo deve ser criteriosa, considerando diferentes alternativas (Wagner et al., 1998). O modelo WAVE oferece opção de escolha entre diversas dessas relações funcionais, incluindo a possibilidade de consideração do fenômeno de histerese. Essas relações funcionais são escritas em função de parâmetros, que podem ser determinados através de técnicas de 
ajuste a partir de pontos experimentais das curvas $K(h)$ e $\theta(h)$, ou através de experimentos específicos, em alguns casos. Ainda, para estimativa dos parâmetros das relações funcionais, ou de pontos das curvas $K(h)$ e $\theta(h)$, pode-se utilizar metodologias indiretas, como as funções de transferência hidropedológica (Montenegro e Montenegro, 1997; Tomasella \& Hodnett, 1998; Ragab \& Cooper, 1990). Os principais parâmetros de água no solo contidos em algumas dessas relações funcionais são: umi-

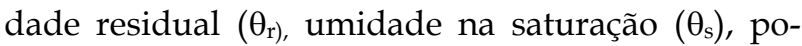
tencial à entrada de ar $\left(\mathrm{h}_{\mathrm{ae}}\right)$, índice de tamanho dos poros $(\lambda)$, e condutividade hidráulica saturada $\left(\mathrm{K}_{\text {sat }}\right)$. Esses parâmetros são características dos solos, e portanto é esperado a sua variabilidade espacial em situações de campo. A variabilidade espacial desses parâmetros tem influência reconhecida nos processos de fluxo de água e transporte de soluto no solo, conforme anteriormente citado.

A quantidade de sais presentes na água disponível para a cultura pode influenciar no fenômeno da transpiração e, por conseqüência, na produtividade da cultura. Idealmente, modelos determinísticos de fluxo na zona não saturada do solo para análise de risco de salinização deveriam incluir os efeitos de estresse hídrico e salino na quantidade de água extraída pela planta. Assim, a função de redução da transpiração na Equação (3), $\alpha(\mathrm{h})$, deveria considerar o efeito do potencial osmótico, que é a parcela do potencial total devido à presença de solutos na água do solo, e não apenas do potencial matricial. O modelo WAVE foi modificado para que a função de redução, $\alpha$, incorporasse também os efeitos da presença de sais de acordo com o modelo proposto por Van Genuchten (1987), conforme descrito em Montenegro (1997). No entanto, para a análise apresentada não se levou em consideração o efeito do sal na transpiração da planta.

\section{MODELO CONCEITUAL: \\ VARIABILIDADE ESPACIAL DOS PARÂMETROS DE ÁGUA NO SOLO}

O modelo conceitual definido inclui a consideração de que o único parâmetro estocástico é a condutividade hidráulica saturada, baseado em estudos publicados que indicam ser esse o parâmetro dominante em termos de heterogeneidade ou variabilidade espacial, entre os diversos parâmetros de água no solo (Jury et al., 1992; White, 1988). A distribuição de probabilidade desse parâmetro e a sua estrutura de correlação, identificada em análise geoestatística, são a base do procedimento estocástico proposto. Considera-se, portanto, nesse caso a análise estocástica univariada, para efeito de demonstração da aplicação da metodologia e da importância dos resultados obtidos para o controle ambiental. Uma análise multivariada, embora com maior demanda computacional, pode ser efetuada, caso se julgue relevante o impacto dessa consideração nos resultados.

$\mathrm{Na}$ análise do transporte de solutos em solos heterogêneos com pouca profundidade, a convecção é o mecanismo preponderante (Butters \& Jury, 1989). Dessa forma, o efeito de escala reconhecidamente existente no coeficiente de dispersão para maiores profundidades (Sposito et al., 1986; Russo, 1993) não precisa ser considerado na análise do problema de transporte a pequenas profundidades, e valores obtidos a partir de experimentos em colunas de solo podem ser utilizados na modelagem com a equação de convecção-dispersão, sem considerar variabilidade vertical e espacial (Amoozegar-Fard et al., 1982).

\section{ANÁLISE ESTOCÁSTICA}

O procedimento de análise estocástica pode ser descrito sumariamente da seguinte forma:

\section{Análise estatística}

A partir de observações pontuais da variável aleatória $\left(\mathrm{K}_{\mathrm{sat}}\right)$, infere-se a sua distribuição de probabilidades, ou os momentos estatísticos que a representam.

\section{Análise geoestatística}

A partir das observações pontuais da variável aleatória, em conjunto com as suas coordenadas espaciais, aplica-se metodologia geoestatística para inferir modelo de estrutura de correlação através do semi-variograma (Journel \& Huijbregts, 1978). A variável aleatória na terminologia geoestatística é denominada variável regionalizada, justificada por sua variação espacial não ter caráter completamente aleatório, sendo função da distância de separação entre pontos de observação no campo. $\mathrm{O}$ semi-variograma, ou simplesmente variograma, relaciona a metade da variância (semi-variância) de valores pontuais observados da variável aleatória 
com a distância de separação desses pontos. Essa etapa inclui a estimativa do variograma experimental, o seu ajuste a diversos modelos teóricos, ou seja, a sua parametrização, e procedimentos de validação e seleção do melhor modelo teórico, e seus parâmetros, que representa adequadamente o comportamento espacial da variável no domínio em estudo.

\section{Interpolação}

Com base no modelo de variabilidade espacial e nas observações pontuais, procede-se a interpolação da variável regionalizada em pontos definidos do domínio (plano horizontal), que correspondem aos nós dos elementos (colunas de solo) da malha da modelagem matemática. Essa interpolação é feita através do Método de Kriging. Como o Método de Kriging é apenas um interpolador, há uma tendência à suavização da heterogeneidade natural pela sua aplicação.

\section{Geração de possíveis cenários de variabilidade espacial}

O Método de Kriging apenas interpola a variável em pontos onde a mesma não foi determinada, mas não considera o efeito da incerteza associada à variabilidade espacial e a erros de determinação dessa variável, que caracterizam a estocasticidade. Essa interpolação corresponde a apenas um dos possíveis cenários de variabilidade espacial da variável em questão. Para se realizar a análise estocástica de problema de fluxo e transporte em meio poroso é necessário a geração de cenários sintéticos da propriedade considerada, todos igualmente prováveis e com a mesma distribuição de probabilidade, e mesma estrutura de correlação dos valores pontuais observados (Zimmerman \& Wilson, 1990), que são descritos através dos modelos inferidos de acordo com os itens "Análise estatística" e "Análise geoestatística". Esses cenários irão conter valores da propriedade em pontos não amostrados e portanto o Kriging é a base para esse procedimento, juntamente com o modelos de probabilidade e geoestatístico inferidos. Cenários não-condicionais ou condicionais podem ser gerados. Em ambos os casos o modelo de variabilidade espacial é utilizado, mas apenas nas chamadas simulações condicionais os valores observados dos parâmetros são reproduzidos nos pontos de observação.

\section{Experimento de Monte Carlo}

A análise estocástica propriamente dita, segundo o método de simulação de Monte Carlo (Zielinsk, 1993), consiste em realizar sucessivas simulações com o modelo determinístico de fluxo e transporte para cada coluna de solo, para o conjunto de possíveis cenários de representação do domínio, e considerando as condições de contorno e iniciais definidas de acordo com o problema em análise. As repetidas simulações permitem determinar o padrão de comportamento espacial das variáveis de saída, correspondendo ao conjunto de colunas de solo representando o domínio, para o conjunto de possíveis cenários espaciais. As variáveis de saída (fluxo e transporte) são determinadas, portanto, em termos probabilísticos através da distribuição de probabilidade inferida para cada locação.

A solução de problemas não lineares, como o fluxo em meios não saturados descrito pela equação de Richards, Equação (1), seguindo o experimento de Monte Carlo é caracterizada por uma elevada demanda computacional, em razão do elevado número de simulações determinísticas. Ao invés de determinar a função densidade de probabilidade da variável estocástica de saída desejada realizando um grande número de simulações determinísticas, por exemplo 50 realizações, através da quadratura da função de distribuição de probabilidade da variável aleatória de entrada, conforme prevê o experimento de Monte Carlo, pode-se proceder a uma aproximação conforme sugerido, por exemplo, por Bresler \& Dagan (1983) e Govindaraju et al. (1992). A função acumulada de probabilidade é dividida em um certo número de classes, e o valor da variável no centro de cada intervalo de classe é considerado para avaliar numericamente as integrais, definindo assim o primeiro e segundo momentos estatísticos das variáveis estocásticas de saída. O número de intervalos de classe deve ser escolhido de maneira a proporcionar economia de tempo nas simulações e não comprometer a precisão da análise.

\section{ANÁLISE DE RISCO DE SALINIZAÇÃO}

Além da avaliação dos cenários de variabilidade espacial de $\mathrm{K}_{\text {sat, }}$ conforme descrito anteriormente, a simulação com o modelo determinístico requer a definição de outros elementos como:

- dados climatológicos: precipitação, evaporação (para a definição da condição de con- 
torno superior, única para todas as colunas de solo que compõem a área);

- dados hidro-agrícolas: calendário de culturas, consumo de água pela cultura, taxas de aplicação de irrigação (para a definição da condição de contorno superior);

- dados de profundidade do lençol freático e sua variabilidade no período de simulação (condição de contorno inferior);

- estimativas de distribuição de umidade e concentração ao longo das profundidades das colunas de solo no início da simulação (condição inicial);

- qualidade da água de irrigação (concentração), para a especificação da condição de contorno superior de transporte;

- parâmetros determinísticos:

- fluxo: parâmetros relacionados às curvas de condutividade hidráulica e tensãoumidade;

- transporte: coeficiente de dispersão hidrodinâmica.

Especificadas as condições iniciais e de contorno, e os parâmetros do sistema solo-água-planta atmosfera, a análise estocástica proposta permite identificar, a partir do conhecimento das distribuições de probabilidade das variáveis de saída no domínio, elementos importantes ao planejamento de uso do sistema de maneira a controlar os efeitos da salinização, como por exemplo:

- percentagem de determinado lote irrigado que sofrerá redução de produtividade de cultura devido a concentração salina da água no solo;

- quantificação da redução de produtividade da cultura em determinado lote ao longo do período de irrigação considerando águas de diferentes qualidades (teores salinos).

A análise de risco permite testar diferentes condições de uso do sistema de maneira a escolher situações menos desfavoráveis com relação ao efeito da acumulação de sais. Pode-se analisar por exemplo:

- efeito do aumento da lâmina de irrigação, visando maior lixiviação de sais;

- alternativas de uso de diferentes culturas (com menor sensibilidade à concentração de sais);
- alternativas de uso de diferentes lotes em função do tipo de solo.

A análise permite também avaliar a qualidade, em termos de concentração de sais, da água de recarga ao lençol.

Baseada nas respostas das simulações de fluxo e transporte na zona não saturada de solo, a análise de risco de salinização pode incluir a avaliação da redução da produtividade (menor crescimento) da cultura em função da salinidade da água disponível para a transpiração. O modelo proposto por Maas \& Hoffman (1977) para estimativa da produtividade das culturas em função da salinidade da água no solo é um dos mais aceitos na literatura especializada. Os autores se basearam em uma densa quantidade de informações sobre tolerância de culturas à salinidade e propuseram um modelo que considera que o máximo valor de produtividade da cultura, sem estresse salino, é mantido até um certo valor limite de salinidade. A partir desse valor limite, a cultura apresentaria um decaimento aproximadamente linear de produtividade percentual relativa. $\mathrm{O}$ modelo pode ser escrito como:

$$
\mathrm{Y}_{\mathrm{r}}=\left\{\begin{array}{lr}
100 & 0 \leq \mathrm{K}_{\mathrm{e}} \leq \mathrm{K}_{\mathrm{a}} \\
100-\mathrm{K}_{\mathrm{b}}\left(\mathrm{K}_{\mathrm{e}}-\mathrm{K}_{\mathrm{a}}\right) & \mathrm{K}_{\mathrm{a}}<\mathrm{K}_{\mathrm{e}} \leq \mathrm{K}_{0} \\
0 & \mathrm{~K}_{\mathrm{e}}>\mathrm{K}_{0}
\end{array}\right.
$$

onde $\mathrm{Y}_{\mathrm{r}}$ é a produtividade percentual relativa da cultura; $K_{a}$ a salinidade limite; $K_{0}$ a salinidade a partir da qual a produtividade é nula; $K_{e}$ a salinidade média na zona das raízes e; $K_{b}$ a declividade da função de produtividade entre $\mathrm{K}_{\mathrm{a}}$ e $\mathrm{K}_{0}$.

A salinidade na Equação (5) pode ser expressa em termos de concentração, potencial osmótico ou condutividade elétrica da solução da água do solo ou do extrato da pasta de saturação (considerando a situação em que o solo está saturado). Maas (1986) apresenta os valores de $K_{b}$ e $K_{a, \text {, em }}$ termos de condutividade elétrica do extrato de saturação, para diferentes culturas. Os dados e o modelo são aplicáveis a solos cujo cloreto é predominante na composição iônica do sal, que é em geral o caso de solos com problemas de salinização secundária. O modelo de Maas \& Hoffman (1977), embora com restrições, é apontado como útil para as tomadas de decisão no gerenciamento da irrigação envolvendo riscos de salinização. Outros modelos são propostos na literatura como o de Cardon \& Letey (1992), mas a presente análise é baseada no modelo de Maas \& Hoffman (1977). 


\section{ÁREA DE ESTUDO E DADOS UTILIZADOS}

A aplicação da metodologia apresentada exige grande quantidade e diversidade de informações. Algumas informações necessárias foram assumidas de forma hipotética para apresentação em um exemplo de aplicação da metodologia.

Como estudo de caso adotou-se uma área irrigada da Fazenda Nossa Senhora do Rosário (Pesqueira, PE). A área está localizada sobre um aqüífero aluvial raso com profundidades do lençol que variam espacial e sazonalmente entre 2,0 e $5,0 \mathrm{~m}$. O aqüífero tem profundidade média de $10 \mathrm{~m}$, e cerca de $300 \mathrm{~m}$ de largura e $15 \mathrm{~km}$ de extensão. $\mathrm{O}$ município de Pesqueira está localizado na região Agreste do Estado de Pernambuco, exibindo clima semi-árido muito quente. A precipitação média anual é de $730 \mathrm{~mm}$, enquanto que a evapotranspiração potencial é de $1638 \mathrm{~mm}$. A fazenda é área de assentamento do governo estadual, possui cerca de 60 ha agricultáveis, divididos em cerca de 50 lotes. Atualmente, a área efetivamente cultivada não excede 20 ha, e diversos lotes encontram-se degradados por salinização. A irrigação utiliza água captada através de quatro poços públicos e quatorze poços construídos pelos próprios agricultores, todos tipo "Amazonas".

Para a caracterização geoestatística da zona não-saturada foram utilizados dados de 55 locações na área, e em três profundidades distintas: 30, 90 e $250 \mathrm{~cm}$. Os pontos de amostragem foram locados aleatoriamente na área. As distâncias mínima e máxima de separação entre os pontos de observação correspondem a 5 e 1400 metros, respectivamente.

As amostras foram analisadas em laboratório para determinação da textura. Esses dados foram utilizados para cálculo da condutividade hidráulica saturada $\left(K_{\text {sat }}\right)$ através de funções de transferência hidropedológica (FTH). Um total de 42 amostras, incluindo as três profundidades, foi utilizado para testar diversas FTH para o cálculo da condutividade hidráulica saturada, comparando com valores de ensaios de laboratório utilizando permeâmetro. As amostras utilizadas em laboratório foram indeformadas, buscando-se preservar as características de campo, quanto à estrutura do solo. Montenegro (1997) detalha os procedimentos de coleta de amostras em campo e ensaios em laboratório de condutividade hidráulica para seleção das FTH. A descrição do processo de teste e seleção da FTH de melhor adequação é apresentado por Montenegro e Montenegro (1997).
Como hipótese da modelagem estocástica pretendida, $\mathrm{K}_{\text {sat, }}$ em cada locação, é avaliado por um valor médio no perfil. Em cada locação foi considerado o valor médio dos logaritmos de $\mathrm{K}_{\text {sat, }}$ tomando-se as três profundidades amostradas, representando uma coluna de solo homogênea, o que representa na verdade a média geométrica dos valores de condutividade hidráulica saturada ao longo da profundidade. Esse critério decorre do fato da condutividade hidráulica seguir usualmente uma distribuição do tipo log-normal, segundo observado por Freeze (1975). De acordo com análise estatística, a variável aleatória $\log \left(\mathrm{K}_{\text {sat }}\right)$ segue aproximadamente uma distribuição de probabilidades do tipo normal. As análises estatística e geoestatística, incluindo o ajuste à distribuição estatística teórica, o ajuste, validação e seleção do semi-variograma paramétrico, são descritas em Montenegro et al. (1999). Para a análise geoestatística, a variável $\log \left(\mathrm{K}_{\text {sat }}\right)$ foi assumida como possuindo comportamento isotrópico na área.

O Método de Kriging foi aplicado em uma malha composta por elementos de dimensão 10 x 10 m, no plano horizontal. Para a aplicação da metodologia, foi selecionado um dos lotes irrigados da Fazenda Nossa Senhora do Rosário com cerca de 0,9 ha. Seguindo o modelo conceitual adotado, a área do lote foi considerada como composta de 90 colunas de solo paralelas e independentes em termos de fluxo e transporte. Após a realização de testes preliminares, foi assumido que 50 realizações (cenários espaciais) do logaritmo da condutividade hidráulica saturada (média no perfil) proporcionava uma precisão adequada para a estimativa da função densidade de probabilidade das variáveis estocásticas de saída (fluxo e transporte). Nesse caso, considerando as 90 locações e o número de cenários, 4.500 simulações determinísticas seriam necessárias. Alternativamente, a distribuição de probabilidade inferida do logaritmo de $K_{\text {sat }}$ foi discretizada em 231 intervalos de classe, de maneira que a diferença entre os extremos entre cada intervalo de classe não fosse inferior a duas ordens de magnitude da variável $\left(\log \left(\mathrm{K}_{\mathrm{sat}}\right)\right.$ em $\left.\mathrm{cm} / \mathrm{s}\right)$. A precisão desse critério foi testada realizando 4500 simulações de um exemplo e comparando com o resultado em termos probabilísticos das 231 simulações, tendo-se obtido boa concordância entre os resultados.

Os dados climatológicos foram obtidos de uma estação distante aproximadamente $15 \mathrm{~km}$ do domínio de estudo. Piezômetros foram instalados na área e monitoramento contínuo com freqüência 


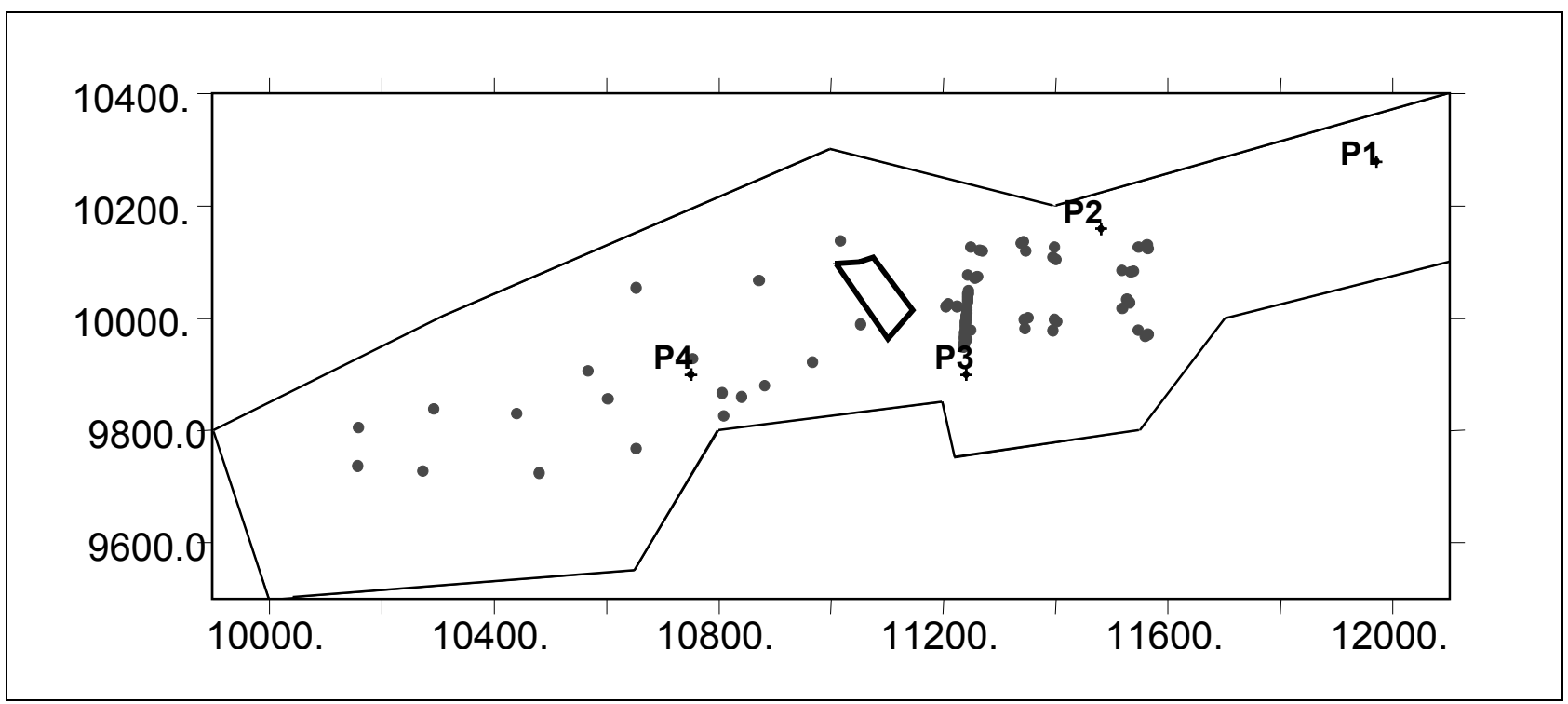

Figura 1. Mapa esquemático da Fazenda identificando os quatro poços públicos, as locações dos pontos amostrais e o lote analisado.

mensal foi efetuado para obtenção dos dados de profundidade do lençol freático. O coeficiente de dispersão hidrodinâmica foi obtido através de experimentos de laboratório em amostras indeformadas de solo, descritos por Montenegro (1997), para determinação de pontos da curva de passagem de soluto e posterior ajuste por regressão a soluções analíticas.

De acordo com a formulação proposta, apenas o logaritmo da condutividade hidráulica saturada seria considerado como variável estocástica, com os demais parâmetros de água no solo constantes para todas as colunas de solo compondo o domínio de estudo. A condutividade hidráulica saturada, assim como os demais parâmetros hidráulicos da zona não saturada, variam de acordo com o tipo de solo. Alternativamente, aplicou-se um outra formulação considerando que os parâmetros das curvas de condutividade hidráulica e tensão-umidade do solo variam em função da condutividade hidráulica saturada. Rawls \& Brakensiek (1982) e Saxton et al. (1986) propuseram FTH para os diversos parâmetros hidráulicos das relações funcionais usuais para $K(h)$ e $\theta(h)$. Utilizando valores de textura de amostras de solo da área, valores de parâmetros hidráulicos foram calculados pelas diferentes expressões propostas, incluindo $\mathrm{K}_{\text {sat. }}$ Equações de regressão foram então derivadas entre cada um dos parâmetros e $\mathrm{K}_{\text {sat, }}$ ou o seu logaritmo, para cada conjunto derivado das diferentes funções, buscando-se o melhor ajuste. As equações obtidas são apresentadas na Tabela 1, juntamente com os coeficientes de determinação do ajuste. Dessa forma, embora utilize-se uma abordagem estocástica com
Tabela 1. Equações de regressão para estimativa de parâmetros das relações funcionais $K(\theta)$ e $\theta(h)$.

\begin{tabular}{lc}
\hline Equação & $\begin{array}{c}\text { Coeficiente de } \\
\text { determinação }\end{array}$ \\
\hline$\theta_{\mathrm{r}}=-0,4141-0,36445 \log \left(\mathrm{K}_{\mathrm{sat}}\right)$ & 0,98 \\
$\log \left(\theta_{\mathrm{s}}\right)=-0,32654-0,00066 \mathrm{Ksat}^{\dagger}$ & 0,89 \\
$\log \left(\left|\mathrm{h}_{\mathrm{ae}}\right|\right)=1,77479-0,00371 \mathrm{~K}_{\text {sat }^{\dagger \dagger}}$ & 0,96 \\
$\log (\lambda)=-0,7757+0,2129 \log \left(\mathrm{K}_{\mathrm{sat}}\right)$ & 0,99 \\
\hline
\end{tabular}

$+\theta_{\mathrm{s}} \geq 0.3 ;+\dagger \mathrm{h}_{\mathrm{ae}} \geq-10 \mathrm{~cm}$.

análise univariada, imprime-se o caráter de variação de outros parâmetros, além da condutividade hidráulica saturada, em função do tipo de solo. Um valor médio igual a $3 \mathrm{~cm}$ para o coeficiente de dispersão hidrodinâmica, $\lambda_{1}$, foi adotado, considerando os testes de laboratório (Montenegro, 1997).

O lote selecionado é usualmente cultivado com beterraba, de março a junho, e cenoura, de setembro a novembro. No entanto, tais condições podem variar, dependendo de vários fatores, como valor de mercado para comercialização do produto. Durante o período de cultivo, o lote é irrigado diariamente. Informações sobre a irrigação não são precisas. Assim, assume-se que o lote é irrigado por aproximadamente 4 horas no turno da manhã, estimando-se uma taxa de aplicação de $5 \mathrm{~mm} /$ dia. A água utilizada para a irrigação do lote é proveniente do poço $\mathrm{P} 2$, apesar do poço mais próximo ser o poço P3 (Figura 1). Portanto, informações de salinidade da água de irrigação foram consideradas 


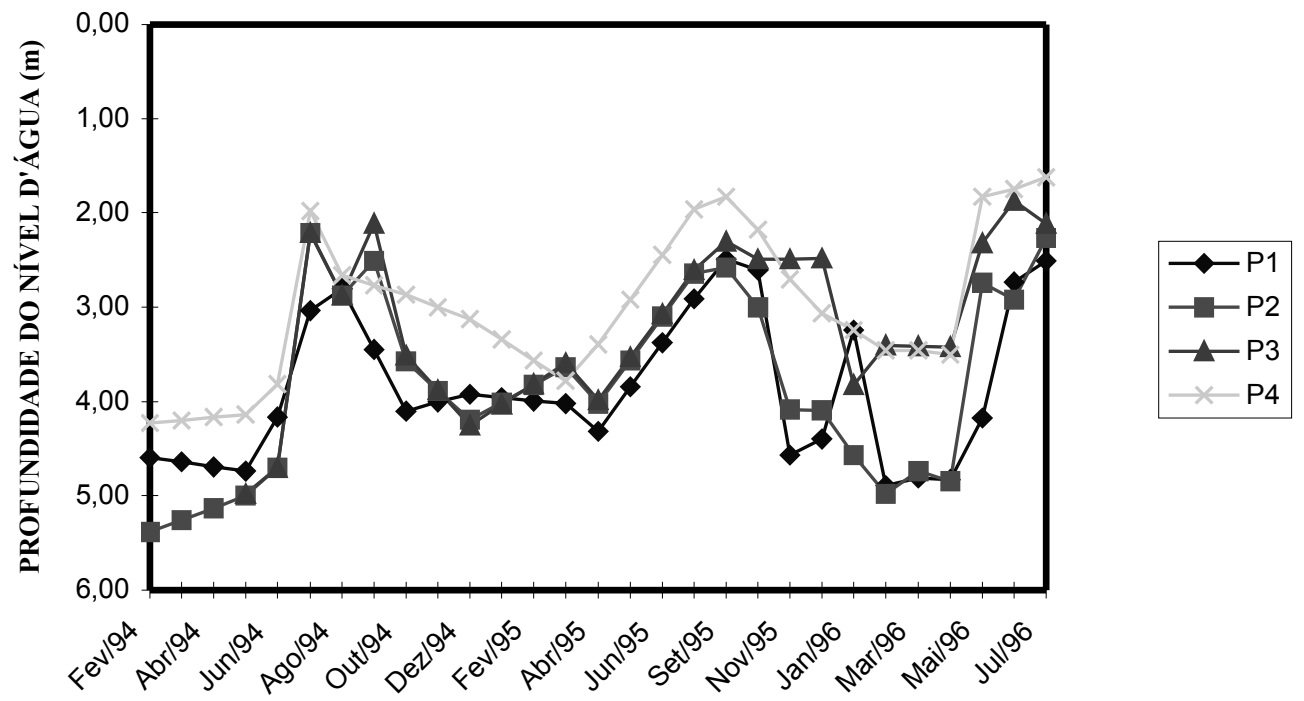

Figura 2. Profundidade do nível d'água nos quatro poços monitorados.

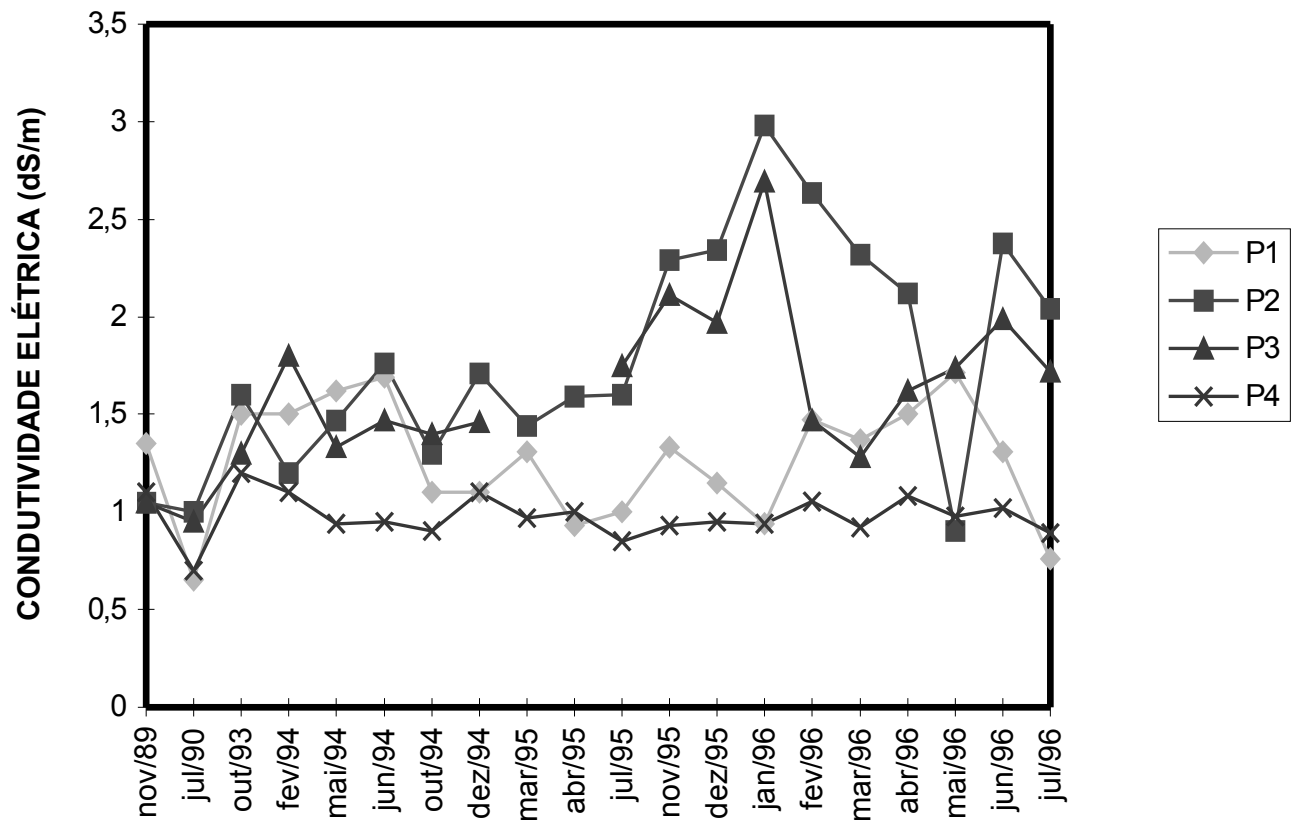

Figura 3. Condutividade elétrica da água subterrânea $(\mathrm{dS} / \mathrm{m})$ nos poços monitorados.

para o poço P2, enquanto os dados do nível d'água no lençol foram tomados como os do piezômetro próximo ao poço P3. Os dados dos quatro poços públicos são apresentados na Figura 2 e Figura 3. Os dados mensais de nível d'água e salinidade no aqüífero foram interpolados, assumindo uma variação linear, para gerar valores diários. O nível d'água do lençol foi assumido uniforme na área do lote.
O modelo WAVE admite dados de entrada a nível diário. É assumido que precipitação, evaporação e irrigação diários são uniformemente distribuídos durante o dia. Devido ao calendário de irrigação adotado, com quatro horas de aplicação diária e taxa uniforme, procedeu-se a uma alteração no modelo WAVE para permitir que a entrada de dados fosse efetuada considerando intervalos de 


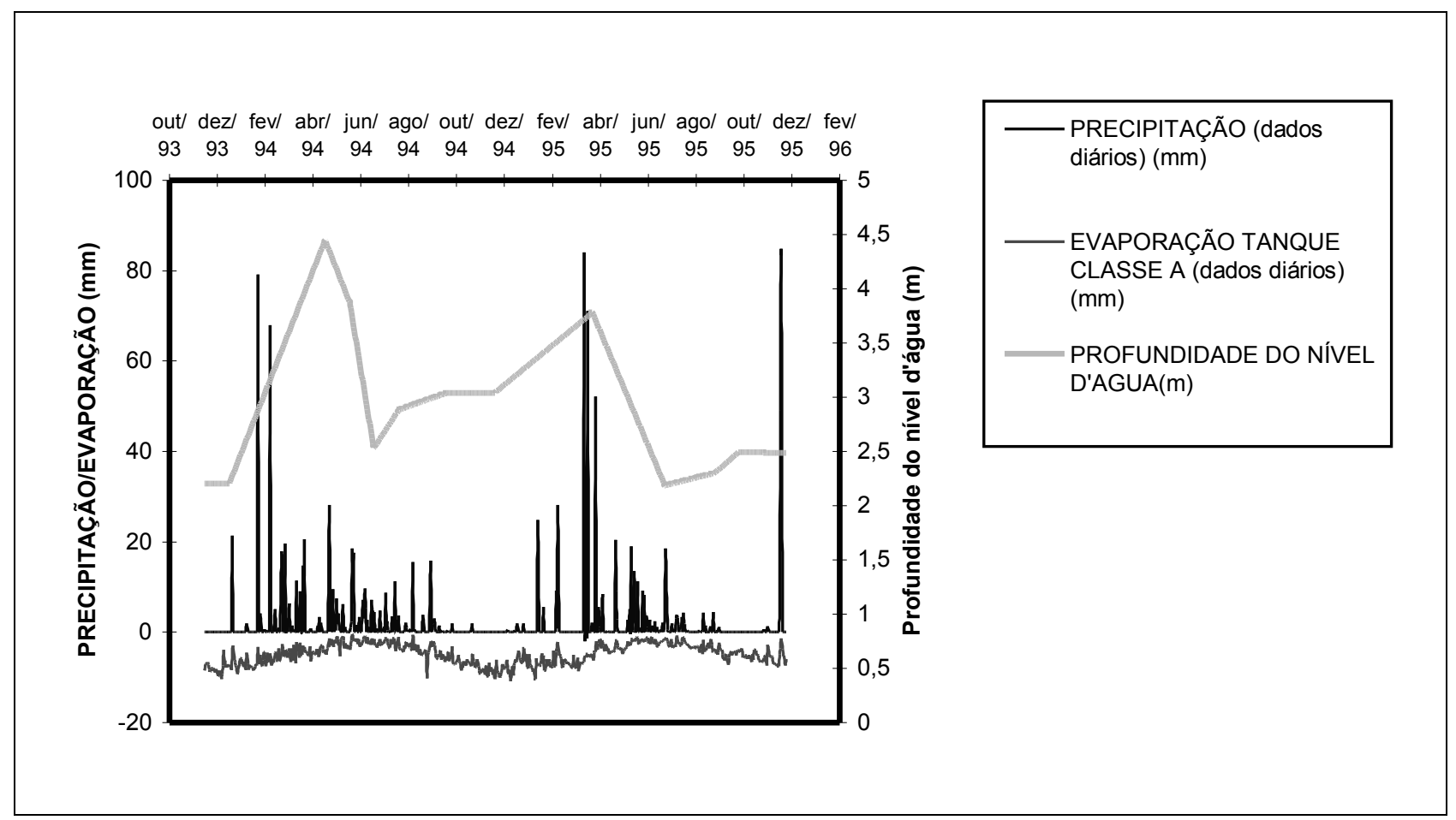

Figura 4. Dados de precipitação, evaporação e profundidade do nível d'água no poço para o período da simulação.

quatro horas. Nível d'água no lençol foi suposto constante durante o dia, e precipitação e evaporação diárias foram repartidas de maneira uniforme nos intervalos que compõem o dia. $\mathrm{O}$ modelo WAVE também foi modificado para permitir simulações em períodos superiores a um ano. Os dados diários de precipitação e evaporação do tanque Classe A e os valores interpolados do nível d'água no lençol no período de simulação são apresentados na Figura 4.

A Tabela 2 apresenta os valores do modelo de Maas \& Hoffman (1986), Equação (6), para estimativa da produtividade da cultura. Os dados das culturas necessários à simulação, coeficiente de cultura, índice de cobertura foliar e profundidade das raízes, foram extraídos da literatura (Molle \& Cadier, 1992; CISAGRO, 1990). Foram assumidos padrões de variação para o índice de cobertura foliar, coeficiente de cultura e profundidade das raízes, durante o período de simulação. Os dados assumidos para efeito de simulação são apresentados na Tabela 3. Os valores de $h_{0}, h_{1}, h_{2}, h_{3}$, a e b, Equações (3) e (4), foram tomados de acordo com sugestões na literatura (Feddes et al., 1978; Hoogland et al., 1981), bem como através de testes de sensibilidade com o modelo para diferentes tipos de solo, selecionando os valores que não restringiam a extração de água pelas raízes, situação mais
Tabela 2. Valores das constantes do modelo de Maas \& Hoffman (1977) para as culturas cultivadas no lote em análise.

\begin{tabular}{lcc}
\hline Cultura & $\mathrm{K}_{\mathrm{a}}(\mathrm{dS} / \mathrm{m})$ & $\mathrm{K}_{\mathrm{b}}(\mathrm{dS} / \mathrm{m})$ \\
\hline Beterraba* & 2,8 & 9,2 \\
Cenoura & 1,0 & 14,0 \\
\hline
\end{tabular}

* a condutividade elétrica do extrato de saturação não deve exceder $3 \mathrm{dS} / \mathrm{m}$ durante o período de germinação.

desfavorável em termos de acúmulo de sais no perfil. A Tabela 4 apresenta os valores adotados para esses parâmetros.

Para o modelo de fluxo de água, a condição de contorno superior assumida para a simulação é de fluxo especificado. A condição de contorno inferior assumida é a de posição do nível d'água especificado. Para o modelo de transporte, a condição de contorno superior adotada é de fluxo especificado na superfície do solo. Os fluxos são calculados através dos dados de entrada de massa de soluto presente na água de infiltração. A precipitação pluviométrica foi assumida como livre da presença de solutos. A massa de sais presente na água de irrigação foi calculada através da condutividade elétrica da água do poço utilizado pela irrigação, monitorado mensalmente. A condição de contorno inferior de transporte foi a de gradiente de concentração nulo na extremidade da coluna de solo. 
Tabela 3. Parâmetros das culturas.

\begin{tabular}{|c|c|c|c|c|c|c|c|}
\hline \multirow{2}{*}{$\begin{array}{l}\text { Cultura } \\
\text { Cenoura }\end{array}$} & \multirow{2}{*}{\begin{tabular}{|l} 
IAF máximo $^{\dagger}$ \\
5
\end{tabular}} & \multirow{2}{*}{$\begin{array}{l}\text { Máxima profundidade } \\
\text { das raízes } *+(\mathrm{cm})\end{array}$} & \multicolumn{5}{|c|}{$\begin{array}{l}\text { Período do ciclo de cultivo (dias) } \\
\text { Coeficiente de cultura }(\mathrm{Kc})^{* * *}\end{array}$} \\
\hline & & & $\begin{array}{c}1-15 \\
0,4\end{array}$ & $\begin{array}{c}15-45 \\
0,6\end{array}$ & $\begin{array}{c}45-75 \\
0,86\end{array}$ & $\begin{array}{c}75-90 \\
0,90\end{array}$ & $\begin{array}{c}90-105 \\
0,8\end{array}$ \\
\hline Beterraba & 6 & 120 & $\begin{array}{l}1-30 \\
0,85\end{array}$ & $\begin{array}{c}30-60 \\
1,05\end{array}$ & $\begin{array}{c}60-91 \\
0,95\end{array}$ & & \\
\hline
\end{tabular}

* Fontes de referência: Molle e Cadier (1992) e CISAGRO (1990); ** valores constantes nos intervalos; † IAF e profundidade das raízes foram assumidos variando linearmente de zero até o máximo valor durante os primeiros 30 dias de irrigação, para a beterraba, e durante os primeiros 45 dias, para a cenoura.

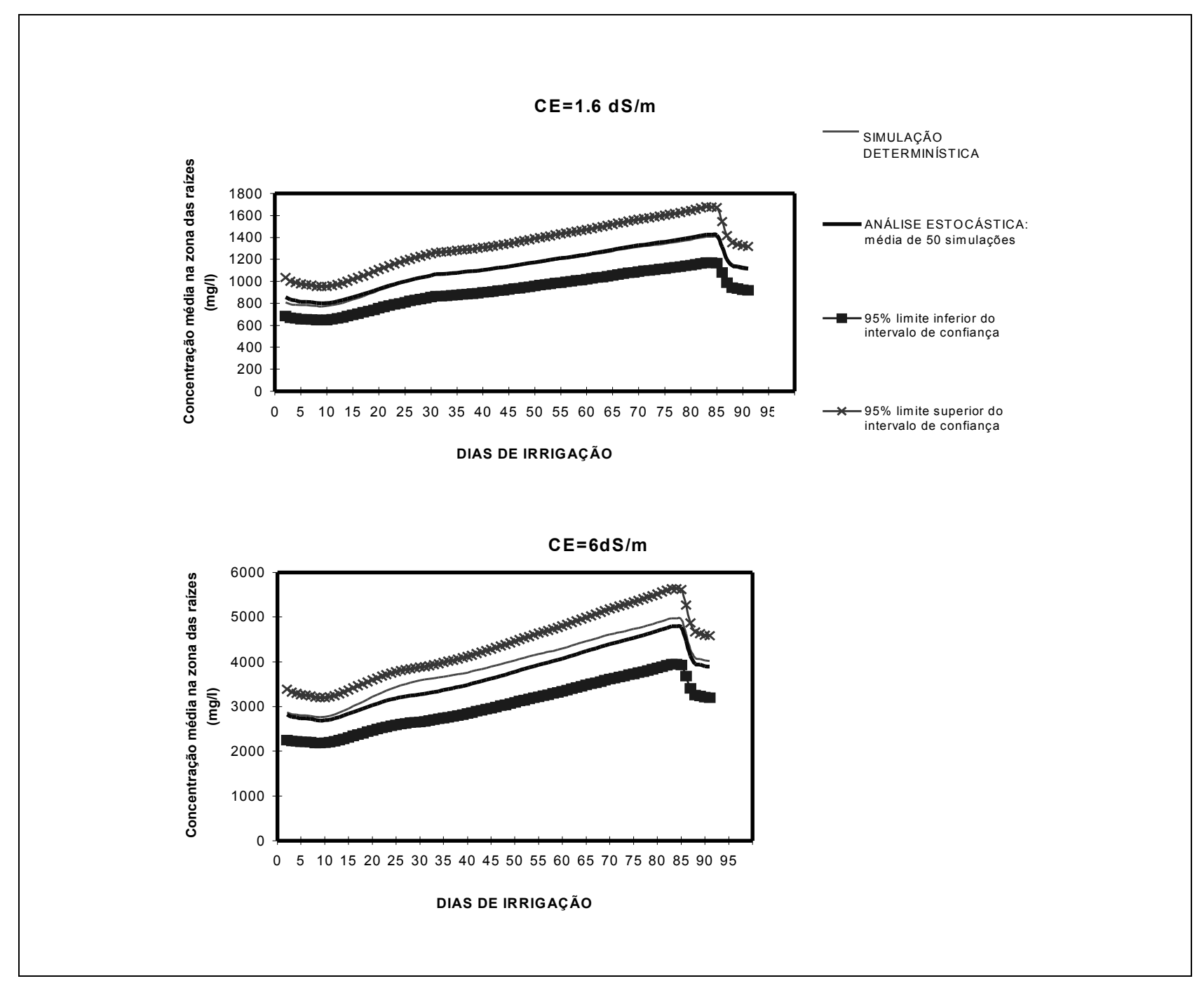

Figura 5. Comparação entre análise estocástica e simulação determinística para dois casos de salinidade (condutividade elétrica, CE) da água de irrigação. 


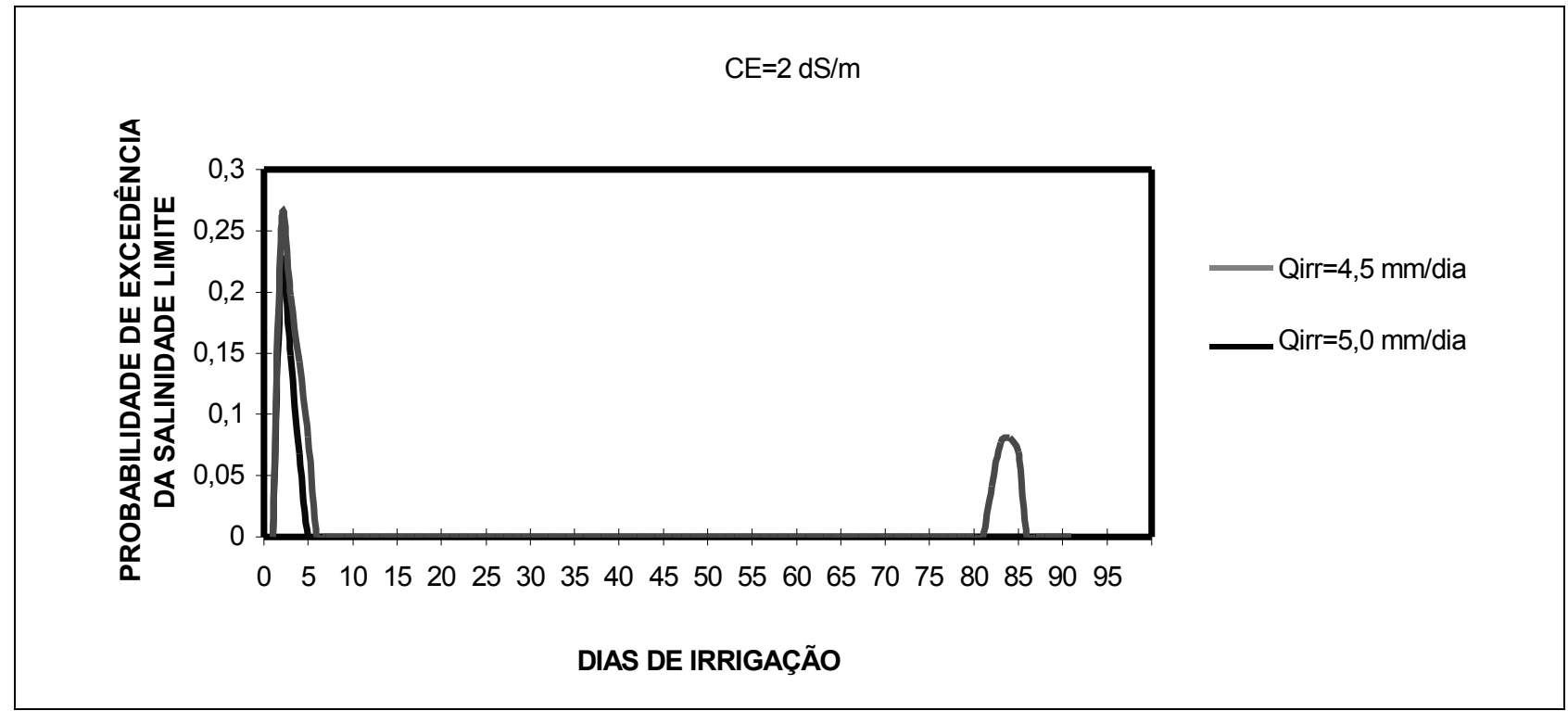

Figura 6. Análise de risco para diferentes lâminas de aplicação da irrigação.

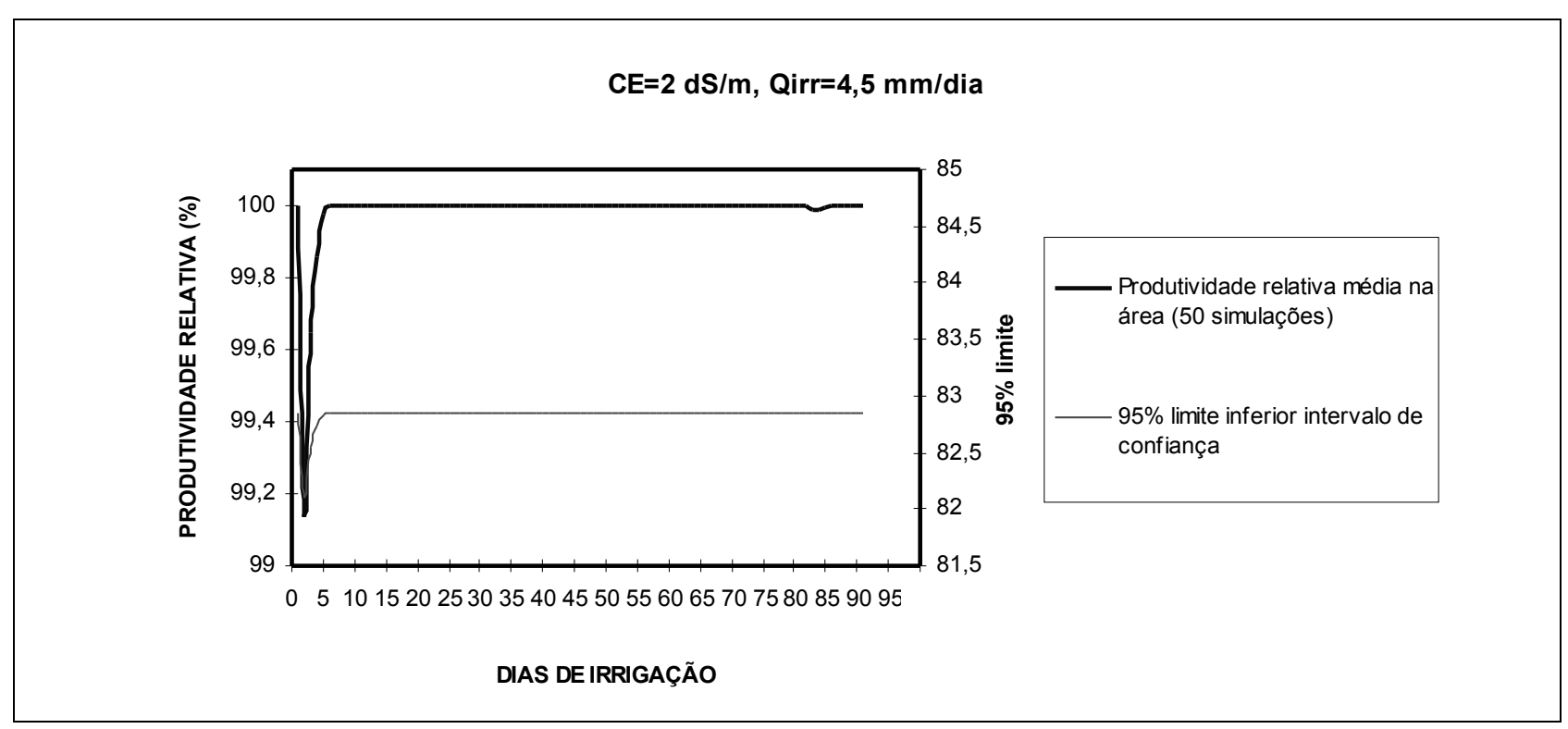

Figura 7. Resultado de análise estocástica: produtividade relativa ao longo do período de irrigação.

Para a simulação de fluxo, a condição de perfil de tensão em equilíbrio com o nível d'água foi considerada. Como o nível d'água foi assumido uniforme na área do lote, o perfil de tensão calculado é único para todas as colunas. O perfil de umidade inicial correspondente para cada coluna é calculado em função da curva tensão-umidade. Um perfil de massa arbitrário foi assumido como condição inicial de transporte para todas as colunas de solo.

As condições iniciais de fluxo e transporte influenciam nas respostas das simulações. Como condições arbitrárias foram assumidas, simulações com as condições de contorno especificadas (fluxo e
Tabela 4. Parâmetros da transpiração máxima, Equação (3), e da função de redução da transpiração, Equação (4).

\begin{tabular}{lr}
\hline Parâmetro & \multicolumn{1}{c}{ Valor } \\
\hline $\mathrm{a}\left(\mathrm{dia}^{-1}\right)$ & 0,018 \\
$\mathrm{~b}\left(\mathrm{dia}^{-1} \cdot \mathrm{mm}^{-1}\right)$ & $1,5.10^{-5}$ \\
$\mathrm{~h}_{0}(\mathrm{~cm})$ & -10 \\
$\mathrm{~h}_{1}(\mathrm{~cm})$ & -50 \\
$\mathrm{~h}_{2}(\mathrm{~cm})$ & -500 \\
$\mathrm{~h}_{3}(\mathrm{~cm})$ & -16.000 \\
\hline
\end{tabular}




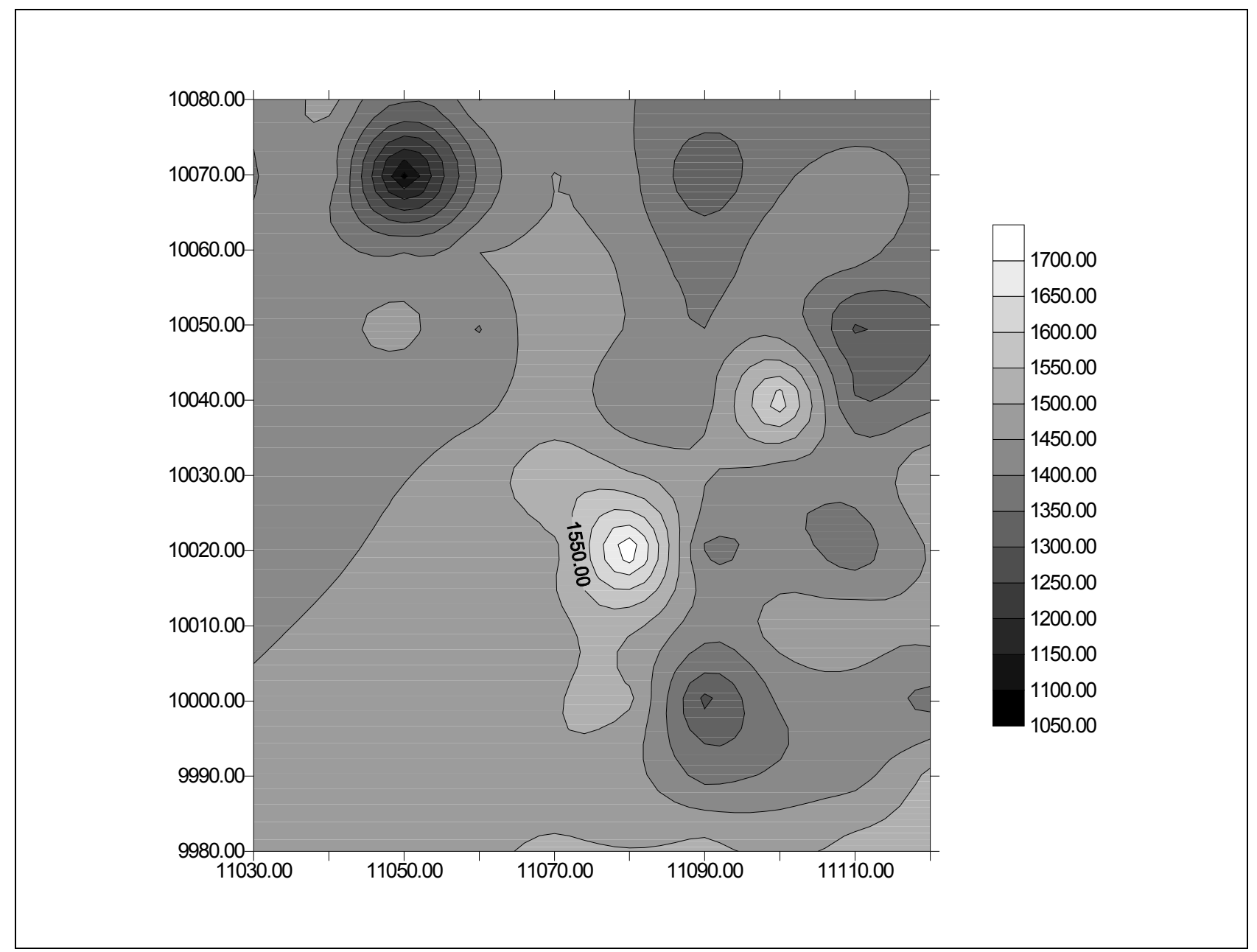

Figura 8. Concentração (média na zona das raízes) $(\mathrm{mg} / \mathrm{l})$ média calculada a partir de 50 realizações de $\log \left(K_{\text {sat }}\right)$ para o dia 89 da simulação.

transporte) foram realizadas buscando a obtenção de solução de equilíbrio em estado permanente. $\mathrm{O}$ período de dados disponíveis para a simulação (Figura 4) é subseqüentemente repetido até que o regime permanente seja atingido.

\section{RESULTADOS E DISCUSSÃO}

A análise realizada foi pretendida como ilustrativa da metodologia proposta, uma vez que diversas hipóteses e aproximações foram adotadas para especificação dos dados de entrada da modelagem. Testes de sensibilidade com algumas das condições hipotéticas de entrada foram realizados, buscando-se avaliar seus impactos na análise estocástica, bem como identificar as necessidades prioritárias para levantamento de informações de campo. Esses testes, seus resultados e discussões não são objeto desse artigo.
Um dos experimentos numéricos realizados permite ressaltar a importância da análise estocástica em relação à simulação determinística. A simulação considerou o cultivo de beterraba por um único período de 89 dias no ano, para cada um dos dois anos do período de dados agroclimatológicos. O período de dados agroclimatológicos de dois anos é repetido em simulações subseqüentes, considerando a saída em termos de umidade e tensão no perfil como entrada ao período de simulação seguinte, até que o regime permanente seja estabelecido. O gráfico da Figura 5 apresenta os resultados da concentração média na zona das raízes para o último período de irrigação, no total de quatro anos de simulação quando o regime permanente foi atingido, para dois diferentes cenários de qualidade da água de irrigação: condutividade elétrica de $1,6 \mathrm{dS} / \mathrm{m}$ e $6 \mathrm{dS} / \mathrm{m}$ (concentração aproximada de 1024 e $3840 \mathrm{mg} / 1$, respectivamente). Os gráficos 


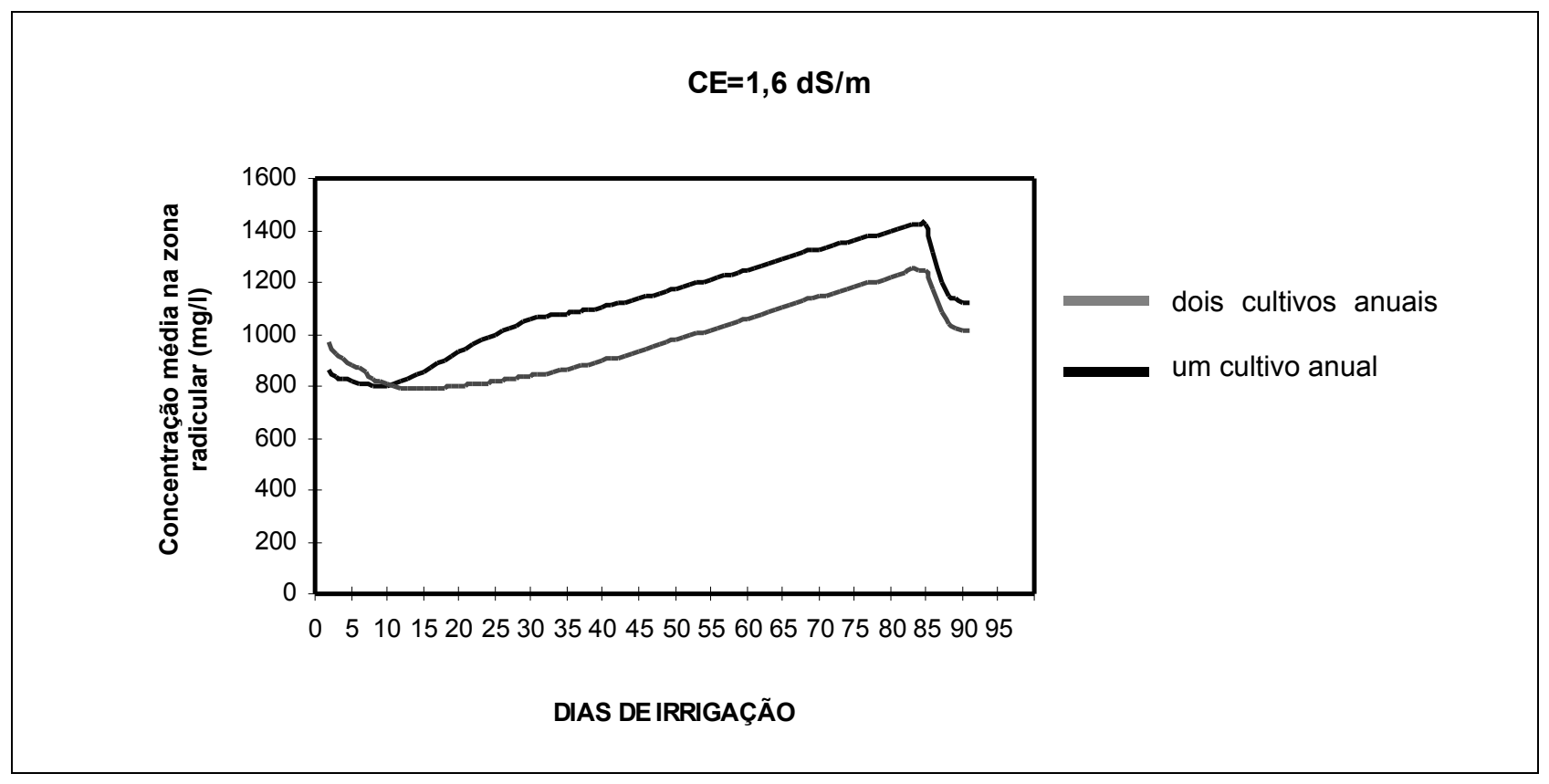

Figura 9. Análise de risco de salinização em função do número de cultivos por ano.

apresentam a comparação entre a concentração para a simulação determinística, considerando uma única coluna de solo com condutividade hidráulica saturada igual ao valor médio da distribuição de probabilidade, e a concentração média da distribuição de probabilidade obtida pela realização do experimento de Monte Carlo, considerando 50 realizações de $\log \left(\mathrm{K}_{\mathrm{sat}}\right)$. Além disso, a partir do experimento de Monte Carlo, é possível determinar diversas características estatísticas da distribuição, como o intervalo com $95 \%$ de confiança para a concentração média na zona radicular ao longo do período simulado. Observa-se da Figura 5 que as diferenças entre as concentrações para a simulação determinística e a análise estocástica são muito pequenas. No entanto, é importante ressaltar que, embora a primeira tenha a vantagem de poder ser executada de maneira bem mais rápida, a simulação determinística não poderia produzir intervalos de confiança, obtidos como resultado da análise estocástica. Além disso, a simulação estocástica permite uma análise de risco do processo de salinização. Essa análise de risco pode ser baseada em outros tipos de resposta da análise estocástica que, por sua vez, não fazem parte da análise determinística. Como exemplo, pode-se determinar qual a probabilidade de excedência da concentração limite, a partir da qual a planta começa a baixar sua produtividade, na área em análise, ao longo do período de cultivo. A Figura 6 ilustra uma aplica- ção desse tipo considerando dois cenários de taxa de aplicação de irrigação. Nesse caso, a probabilidade é equivalente a percentagem da área em que a condutividade limite (média na zona das raízes) é excedida. Os gráficos ilustram que a probabilidade de excedência da salinidade limite, ou o percentual da área em que o limite é excedido, é muito pequena para as condições consideradas na simulação, a exceção de um pico nos primeiros dias de cultivo, justamente uma das fases mais importantes do ponto de vista de desenvolvimento vegetativo e sensibilidade da cultura.

Em uma análise de risco pode-se desejar saber não apenas qual o percentual da área com possibilidade de perda de produtividade, mas também de quanto seria essa redução de produtividade ao longo do ciclo de cultivo. A Figura 7 ilustra o resultado de uma simulação, para um determinado cenário de qualidade da água de irrigação (condutividade elétrica de $2 \mathrm{dS} / \mathrm{m}$ ) e de taxa de aplicação (4,5 mm/dia) enfocando esse tipo de resposta, obtida aplicando o modelo de Maas \& Hofman (1977) ao resultado da simulação (concentração média ao longo da profundidade das raízes) e calculando-se a distribuição de probabilidade. Um mapa de isolinhas produzido com os resultados da simulação pode identificar quais as regiões de maior vulnerabilidade na área analisada (Figura 8). A Figura 9 ilustra a análise de risco de salinização considerando cenários de um ou dois cultivos por ano. 


\section{CONCLUSÕES}

A metodologia de análise estocástica espacial de fluxo de água e transporte de soluto em solos não saturados apresentada nesse trabalho permite avaliar o risco de acúmulo de sais na zona radicular sob diversos cenários de uso da água de irrigação captada de aqüífero freático raso em áreas com altas taxas de evaporação, como acontece no semi-árido do Nordeste brasileiro e outras regiões áridas e semi-áridas do mundo.

O trabalho apresenta aplicação da metodologia a um estudo de caso. Demonstra-se o seu potencial para a análise de risco de salinização. Algumas hipóteses simplificadoras foram assumidas, baseadas em resultados de diversas análises semelhantes reportadas na literatura, como a validade do modelo de colunas paralelas e a consideração da condutividade hidráulica saturada como única variável estocástica. Essas hipóteses devem ser validadas com base na realidade regional, para a garantia da confiabilidade da aplicação da metodologia. Não obstante a alta demanda de informações para o uso da ferramenta, a metodologia apresentada é de extrema importância para a conservação dos recursos naturais em região com elevada vulnerabilidade natural, via de regra submetida à falta de controle na prática de atividades humanas necessárias ao seu desenvolvimento econômico, como a irrigação.

\section{AGRADECIMENTOS}

Os autores agradecem ao $\mathrm{CNPq}$, à Universidade de Newcastle (Inglaterra) à ODA (Overseas Development Admnistration), à UFPE, à UFRPE e à EMATER-PE pelo apoio a parte da pesquisa desenvolvida durante programa de doutoramento do primeiro autor. A pesquisa também recebeu apoio financeiro da FACEPE (Fundação de Amparo à Ciência e Tecnologia do Estado de Pernambuco) e do $\mathrm{CNPq}$, além de ser apoiada pela Universidade de Birmingham (Programa de Cooperação financiado pelo British Council). Os autores também agradecem aos revisores, pelas valiosas sugestões.

\section{REFERÊNCIAS}

AMOOZEGAR-FARD, A.; NIELSEN, D. R. \& WARRICK, A. W. (1982). Soil solute concentration distributions for spatially varying pore water velocities and apparent diffusion coefficients. Soil Sci. Soc. Am. J. 43: 3-9.

ANTONINO, A. C. D.; MONTENEGRO, S. M. G. L.; CARNEIRO, C. J.; CABRAL, J. J. S. P. e MONTENEGRO, A. A. (1998). Estudo numérico da influência das propriedades do solo na determinação da capacidade de campo.

BRESLER, E. \& DAGAN, G. (1983). Unsaturated flow in spatially variable fields, 2. Application of water flow models to various fields. Water Resources Research, vol. 19, n²: 421-428.

BROOKS, R. H. \& COREY, A. T. (1964). Hydraulic properties of porous media. Colorado State University Hydrol. Paper n³, p.27.

BUTTERS, G. L. \& JURY, W. A. (1989). Field scale transport of bromide in an unsaturated soil, 2 . Dispersion modeling. Water Resources Research, vol. 25, n7: 1583-1589.

CAMBARDELLA, C. A.; MOORMAN, T. B.; NOVAK, J. M.; PARKIN, T. B.; KARLEN, D. L.; TURCO, R. F. \& KONOPKA, A. E. (1994). Field - scale variability of soil properties in Central Iowa. Soils. Soil Sci. Soc. Am. J. 58: 1501-1511.

CARDON, G. E. \& LETEY, J. (1992). Plant water uptake terms evaluated for soil water and solute movement models. Soil Sci. Soc. Am. J., 32: 1876-1880.

CARTER, R. C. \& ALKALI, A. G. (1996). Shallow groundwater in the northeast arid zone of Nigeria. Quaterly Journal of Engineering Geology, 29, 341-355.

CISAGRO - COMPANHIA INTEGRADA DE SERVIÇOS AGROPECUÁRIOS (1990). Projeto de irrigação da fazenda Nossa Senhora do Rosario - Pesqueira, PE. Pernambuco, Brazil.

DAGAN, G. \& BRESLER, E. (1979). Solute dispersion in unsaturated heterogeneous soil at field scale: I. Theory. Soil Sci. Soc. Am. J. 43: 461-467.

DAGAN, G. \& BRESLER, E. (1983). Unsaturated flow in spatially variable field soils, 1 . Derivation of models of infiltration and redistribution. Water Resources Research, 19(2): 413-420.

ELLSWORTH, T. R. \& JURY, W. A. (1991). A three- dimensional field study of solute transport through unsaturated, layered, porous media, 1. Methodology, mass recovery, and mean transport. Water Resources Research, 27: 951-965.

FEDDES, R. A.; KOWALIK, P. J. \& ZARADNY, H. (1978). Simulation of field water use and crop yield. PUDOC, Wageningen, $189 \mathrm{p}$.

FREEZE, R. A. (1975). A stochastic conceptual analysis of one - dimensioinal groundwater flow in non homogeneous media. Water Resources Research, 11(5): 725-742.

GHASSEMI, F.; JAKEMAN, A. J. \& NIX, H. A. (1991) Human induced salinisation and the use of quantitative methods. Environment International, vol. 17: 581-594.

GOÉS, E. S. (1978). O problema de salinidade e drenagem em projetos de irrigação do Nordeste e a ação da 
pesquisa com vistas a seu equacionamento. Anais da Reunião sobre Salinidade em Áreas Irrigadas. SUDENE. Fortaleza, CE, 4-24.

GOVINDARAJU, R. S.; OR, D.; KAVVAS, M. L.; ROLSTON, D. E. \& BIGGAR, J. (1992). Error analyses of simplified unsaturated flow models under large uncertainty in hydraulic properties. Water Resources Research, 28 (11): 2913-2924.

HOOGLAND, J. C.; FEDDES, R. A. \& BELMANS, C. (1981). Root water uptake model depending on soil water pressure head and maximum extraction rate. Acta. Hortic., 119: 123-131.

ISTOK, J. D.; BLOUT, O.; BAKER, L.; KOHNEJACK, K. R. \& HAMMERMEISTER, D. P. (1994). Spatial variability in alluvium properties at a low-level nuclear waste site. Soil Sci. Soc. Am. J., 58: 1040-1051.

JOURNEL, A. G. \& HUIJBREGTS, CH. J. (1978). Mining geostatistics. Academic Press. 599p. England.

JURY, W. A.; GARDNER, W. R. \& GARDNER, W. H. (1992). Soil physics. 317p.

JURY, W. A.; RUSSO, D.; SPOSITO, G. \& ELABD, H. (1987). The spatial variability of water and solute transport properties in unsaturated soil. I. Analysis of property variation and spatial structure with statistical models. Hilgardia, 55(4): 1-31.

MAAS, E. V. (1986). Salt tolerance of plants. Applied Agricultural Res., vol. 1, n¹: 12-26.

MAAS, E. V. \& HOFFMAN, G. J. (1977). Crop salt tolerance - current assessment. J. Irrig. and Drainage Div., ASCE, 103 (IR2): 115-134.

MOLLE, F. e CADIER, E. (1992). Manual do pequeno açude. SUDENE, Pernambuco, Brasil. 521p.

MONTENEGRO, S. M G. L. (1997). Stochastic analysis of salt accumulation in heterogeneous irrigated soils: a case study in Northeast Brazil. Newcastle, Inglaterra. 277p. Tese de Ph. D. Department of Civil Engineering. University of Newcastle.

MONTENEGRO, S. M. G. L. \& MONTENEGRO, A. A. de A. (1997). Uso de funções de transferência hidropedológica em uma área irrigada do Estado de Pernambuco visando modelagem espacial estocástica. Anais XII Simpósio Brasileiro de Recursos Hídricos (CD). Vitória. ES.

MONTENEGRO, S. M. G. L.; MONTENEGRO, A. A. de A. e MACKAY, R. (1999). Caracterização da variabilidade espacial de parâmetros hidráulicos em solos aluviais no Estado de Pernambuco. Revista Brasileira de Recursos Hídricos, vol. 4, $\mathrm{n}^{\circ} 2$.

NIELSEN, D. R.; BIGGAR, J. W. \& ERH, K. T. (1973). Spatial variability of field measured soil - water properties. Hilgardia, 42(7):215-259.

NOUR EL - DIN, M. M.; KING, I. P. \& TANJI, K. K. (1987). Salinity management model: I. Development. Journal of Irrigation and Drainage Engineering, vol. 113, n4: 440-453.

PROTOPAPAS, A. L. \& BRAS, R. L. (1991). The onedimensional approximation for infiltration in heterogeneous soils. Water Resources Research, vol. 27: 1019-1027.

RAGAB, R. \& COOPER, J. D. (1990). Obtaining soil hydraulic properties from field, laboratory and predictive methods. Institute of Hydrology, Wallingford. United Kingdon. 83p.

RAWLS, W. J. \& BRAKENSIEK, D. L. (1982). Estimating soil water retention from soil properties. J. Irrig. and Drainage Div. ASCE 108: 166-171.

RUSSO, D. (1984). A geostatistical approach to solute transport in heterogeneous fields and its applications to salinity management. Water Resources Research, vol. 20, n9: 1261-1270.

RUSSO, D. (1991). Stochastic analysis of simulated vadose zone solute transport in a vertical cross section of heterogeneous soil during nonsteady water flow. Water Resources Research, vol. 27, n³: 267-283.

RUSSO, D. (1993). Stochastic modeling of macrodispersion for solute transport in a heterogeneous unsaturated porous formation. Water Resources Research, vol. 29: 383-397.

RUSSO, D. \& BRESLER, E. (1981). Soil hydraulic properties as stochastic processes, I. An analysis of field spatial variability. Soil Sci. Soc. Am. J., 46: 20-26.

RUSSO, D. \& BRESLER, E. (1982). A univariate versus a multivariate parameter distribution in a stochastic conceptual analysis of unsaturated flow. Water Resources Research, 18: 483-488.

SAXTON, K. E.; RAWLS, W. J.; ROMBERGER, J. S. \& PAPENDICK, R. I. (1986). Estimating generalized soil water characteristics from texture. Soil Sci. Soc. Am. J. 50(4): 1031-1035.

SILVA, S. M. P. da (2000). A distribuição espacial das reservas hídricas subterrâneas do Nordeste e a transposição do rio São Francisco. Anais V Simpósio de Recursos Hídricos do Nordeste. Natal, RN. p.47-55.

SPOSITO, G.; JURY, W. A. \& GUPTA, V. K. (1986). Fundamental problems in the stochastic convection - dispersion model of solute transport in aquifers and field soils. Water Resources Research, vol. 22, $\mathrm{n}^{\circ} 1$ : 77-88.

TOMASELLA, J.; M. G. HODNETT. (1998). Estimating unsaturated hydraulic conductivity of Brazilian soils using soil water retention data. Soil Science, vol. 162, n¹0: 703-712.

VANCLOOSTER, M.; VIANE, P.; DIELS, J. \& CHRISTIAENS, K. (1994). WAVE - a mathematical model for simulating water and agrochemicals in the soil and vadose environment. Reference and User's Manual (Release 2.0). Bélgica.

VAN GENUCHTEN, M. Th. (1980). A closed form equation for predicting the hydraulic conductivity of unsaturated soils. Soil Sci. Soc. Am. J., 44: 892-898.

VAN GENUCHTEN, M. Th. (1987). A numerical model for water and solute movement in and bellow the root zone. 
Res. Rep. 121. USDA - ARS, U. S. Salinity Laboratory, Riverside, CA.

WAGNER, B.; TARNAWSKI, V. R.; WESSOLEK, G. \& PLAGGE, R. (1998). Suitability of models for the estimation of soil hydraulic parameters. Geoderma, 86: 229- 239.

WHITE, I. (1988). Measurement of soil physical properties in the field. In: W. L. Steffan and O. T. Denmead (eds). Flow and Transport in the Naturatl Environment: Advances and Applications. Springer Verlag. USA.

WU, Q. J.; WARD, A. D.; WORKMAN, S. R. \& SALCHOW, E. M. (1997). Applying stochastic simulation techniques to a deterministic vadose zone solute transport model. Journal of Hydrology, 197: 88-110.

ZIELINSKI, P. A. (1993). An approximation technique for stochastic environmental modeling. Water Resources Research, vol. 29, n¹0: 3379-3387.

ZIMMERMAN, D. A. \& WILSON, J. L. (1990). Description of and user's manual for TUBA: a computer code for generating two dimensional random fields via the turning bands methods. SEASOFT Scientific \& Engineering Analysis Software, New Mexico. 112p.

\section{Stochastic Analysis of Water Flow and Solute Transport in Unsaturated Soils for Risk Assessment Analysis}

\section{ABSTRACT}

The development of irrigated agriculture and the irregular rain and flow regimes in Northeastern Brazil, in addition to few hydraulic structures in some areas to use the limited water resources, make of groundwater the only alternative for water supply. However, large areas in this region lie over shallow bedrock formations, the crystalline rock basins, characterized by limited groundwater storage capacity and difficulties in locating wells adequately. Thus, small scale agriculture, or family agriculture, has been performed in river valleys, generally with intermittent flow, relying on water from alluvium aquifers. The vulnerability of these systems to salinization, risking water and soil conservation and crop yield, requires the use of tools to diagnose salt accumulation problems, so that adequate irrigation management can be pursued. This paper presents a methodology for spatial stochastic analysis of water flow and solute transport in the unsaturated zone for salinity risk assessment. A case study is presented focusing on an irrigated area supplied by the underlying alluvial aquifer, in Pernambuco state. Examples of potential applications of the methodology are presented. The need for more field data in order to use the methodology is highlighted. The spatial stochastic analysis presented may be applied to other soil water risk assessment problems.

Key Words: salinization; unsaturated zone; alluvial aquifer; spatial variability; stochastic analysis. 